\title{
Exploring bacterial pathogen community dynamics in freshwater beach sediments: A tale of two lakes
}

\author{
Danielle VanMensel (D), ${ }^{\text {* }}$ Subba Rao Chaganti, ${ }^{1,2}$ \\ Ian G. Droppo ${ }^{3}$ and Christopher G. Weisener ${ }^{1}$ \\ ${ }^{1}$ Great Lakes Institute for Environmental Research, \\ University of Windsor, Ontario, Canada. \\ ${ }^{2}$ Cooperative Institute for Great Lakes Research, \\ University of Michigan, Ann Arbor, MI, USA. \\ ${ }^{3}$ Environment and Climate Change Canada, Burlington, \\ Ontario, Canada.
}

\section{Summary}

Pathogenic bacteria associated with freshwater ecosystems can pose significant health risks particularly where recreational water use is popular. Common water quality assessments involve quantifying indicator Escherichia coli within the water column but neglect to consider physical and geochemical factors and contributions from the sediment. In this study, we used high-throughput sequencing to investigate sediment microbial communities at four freshwater public beaches in southern Ontario, Canada and analysed community structure, function, and gene expression with relation to geographical characteristics. Our results indicate that beach sediments at the sediment-water interface could serve as potential sources of bacterial contamination under low-energy environments with tightly packed small sediment particles compared with high-energy environments. Further, the absence of pathogens but expression of pathogenic transcripts suggests occurrence of alternate gene acquisition. Pathogenicity at these locations included expression of Salmonella virulence factors, genes involved in pertussis, and antimicrobial resistance. Finally, we introduce a proposed universal bacterial pathogen model to consider the combined and synergistic processes used by these microbes. To our knowledge, this is the first study of its kind to investigate chemolithotrophic activity related to pathogens within bed sediment at freshwater beaches. This work helps

Received 27 May, 2019; revised 5 November, 2019; accepted 13 November, 2019. *For correspondence. E-mail vanmensd@ uwindsor.ca; Tel. (+519) $2533000 \times 4739$ advance current understanding of health risks in these environments.

Introduction

Pathogen contamination of water resources is a major concern throughout the world. At public beaches, routinely quantifying indicator bacteria (e.g. Escherichia coli) within the water column is common for the assessment of public health risk. However, these simple assessments disregard physical (e.g. energy) and geochemical (e.g. nutrients, redox) factors as well as contributions from the sediment. According to a 2013 U.S. survey (NRDC, 2014), waters in the Great Lakes had the most frequent cases of high beach action value (BAV) E. coli that exceeded acceptable levels. These water quality assessments are often performed during the recreational season (e.g. May to September in the Great Lakes region) and focus on the water compartment only. This approach lacks context with respect to physical factors (e.g. disturbance of nearshore sediments) that require consideration. For instance, storm events can result in the resuspension of bed sediment in the water column within nearshore environments. Past studies have shown that sediment dynamics (i.e. resuspension, erosion, transport, deposition) influence both the temporal and spatial variation in microbial communities in sediment and water compartments (Droppo et al., 2011; Phillips et al., 2014; Reid et al., 2016). In comparison to the water column, benthic sediment microbial communities have been reported to harbour considerably higher concentrations of bacteria (Droppo et al., 2009; Probandt et al., 2018), with more than $99 \%$ of those microbes attached to mineral grains (Rusch et al., 2003). Several studies have documented that sand reservoirs of faecal indicator bacteria (FIB) contribute to beach water samples exceeding regulatory limits (Alm et al., 2003; Beversdorf et al., 2007; Yamahara et al., 2009; Cloutier et al., 2015), although with limited understanding of the sediment bacterial community (i.e. total structure and functional potential). In many cases, the status of the water may not be accurately represented by traditional water quality assessments (e.g. indicator bacterial counts) that resource managers routinely use in water quality monitoring programs. 
In the past 15 years, our ability to track community and compositional changes within the microbiome of environmental ecosystems has improved and benefitted with the introduction of high-throughput sequencing (HTS) (Mohiuddin et al., 2017; Ramirez et al., 2018; Shahraki et al., 2019). These advancements have enabled the detection of species in situ without the limitation of isolating and culturing single organisms, which do not represent larger community dynamics (Handelsman, 2004; Stewart, 2012; $\mathrm{Su}$ et al., 2012). Nevertheless, taxonomic surveys alone can be misleading because they cannot represent the activity (i.e. metabolic status) of the community. The advancement of transcriptomic technology, however, provides higher resolution to observe functional gene expression (Weisener et al., 2017; Reid et al., 2018; Falk et al., 2018). Thus, the insight we gain from messenger RNA (mRNA) can complement taxonomic surveys because it allows us to investigate the functioning community (Goltsman et al., 2015; Crovadore et al., 2017; Zhang et al., 2017), improving our understanding of a microbial system.

Previous studies regarding pathogens in recreational waters have not linked geochemical parameters and physical characteristics/dynamics in conjunction with functional genomics for enhanced insight into the microbial community. To investigate these physicochemical/ microbial relationships, we sampled four public freshwater beaches (two from Lake St. Clair and two from Lake Erie within southern Ontario) and focused on the active microbial community at the sediment-water interface in the nearshore zone. Using functional genomic techniques, we (i) identified the microbial community profile and gene expression within these beach sediments, (ii) characterized the pathogenic potential within the nearshore beaches, and (iii) linked pathogenic gene expression to the local sediment and water characteristics.

\section{Results and discussion}

\section{Beach sediment characteristics}

Windsor-Essex County (WEC) is located between Lake St. Clair and Lake Erie (Fig. 1) and is part of the greater Lake Erie watershed. Four public beaches in WEC were selected for this study based on geochemical and physical characteristics as well as historical water quality data provided by the Windsor-Essex County Health Unit (WECHU); Holiday Conservation beach in Amherstburg (HD) and Lakeside beach in Kingsville (KV) are both located on Lake Erie, and Sandpoint beach in Windsor (SP) and West Belle River beach in Belle River (BR) are both located on Lake St. Clair. Physicochemical analyses of these beaches (e.g. TOC, particle size, energy conditions) were undertaken to demonstrate the variations and similarities between sites within the two lakes. This qualitative and quantitative information assisted with the explanation of analytical bacterial trends, pathogen presence, and the degree of microbial activity.

Tables 1 and 2 provide the different geochemical parameters evaluated. Both SP and HD beaches represented high-energy locations, while BR and KV beaches were influenced by restricted water flow due to adjacent artificial piers and represented low-energy sites as exhibited by coastal embayment and lower wave energy (Table 2). Grain size distribution of bulk bed sediment revealed that $B R$ and $K V$ consisted of finer grains $\left(D_{50}\right.$ of 0.32 and $0.37 \mathrm{~mm}$ respectively) in the nearshore zone compared with SP and $\mathrm{HD}\left(\mathrm{D}_{50}\right.$ were 0.65 and $1.40 \mathrm{~mm}$ respectively); a further suggestion of their lower energy. The close packing of these fine grains at BR and KV results in a decrease in relative porosity and an increase in hydrostatic pressures, which can result in steep vertical geochemical gradients (Chen et al., 2013).

The concentration of DO and measured Eh across the sediment-water interface (Fig. 2) associated with SP and $\mathrm{HD}$ bed sediments was diffuse. In contrast, BR and KV quickly became anoxic as a function of depth and were characterized by sharp DO gradients and measured Eh values across the sediment-water interface. This is partially related to the smaller grain size at $\mathrm{BR}$ and $\mathrm{KV}$ reducing convection and the rate of diffusion of DO to depth within the sediments (Neira et al., 2015). DO was completely consumed within the top $2 \mathrm{~cm}$ of the sediment-water interface at $\mathrm{BR}$ (Fig. 2B) and within the top $1 \mathrm{~cm}$ at KV (Fig. 2D) with a net decrease in concentration of $\sim 260$ and $175 \mu \mathrm{mol} \mathrm{L}^{-1}$ respectively.

Geographically, the beaches represent diverse locations; both $\mathrm{BR}$ and $\mathrm{KV}$ are proximal to adjacent urban tributaries (the Belle River connects with Lake St. Clair at West Belle River beach and Mill Creek reaches Lake Erie at Lakeside beach in Kingsville) while SP and HD are near the inlet and outlet of the Detroit River respectively. Watersheds traversing through urban and agriculture landscapes are well documented as important sources of chemical (i.e. fertilizer and nutrient loadings) and biological (i.e. FIB) contaminants and subsequently influence their downstream deposition zones (Droppo et al., 2011; Kerr et al., 2016). Additionally, compared with other beaches in WEC that are regularly monitored for water quality by WECHU, BR and KV have historically demonstrated high frequencies of indicator $E$. coli counts exceeding acceptable levels (i.e. 100 colony-forming units, CFUs $/ 100 \mathrm{~mL}$ ) in the water column (Fig. $\mathrm{S} 1$ in the Supporting Information).

\section{Sequencing statistics and functional assignments}

For taxonomic analysis derived from recovered DNA, each location consisted of four replicate samples, which 


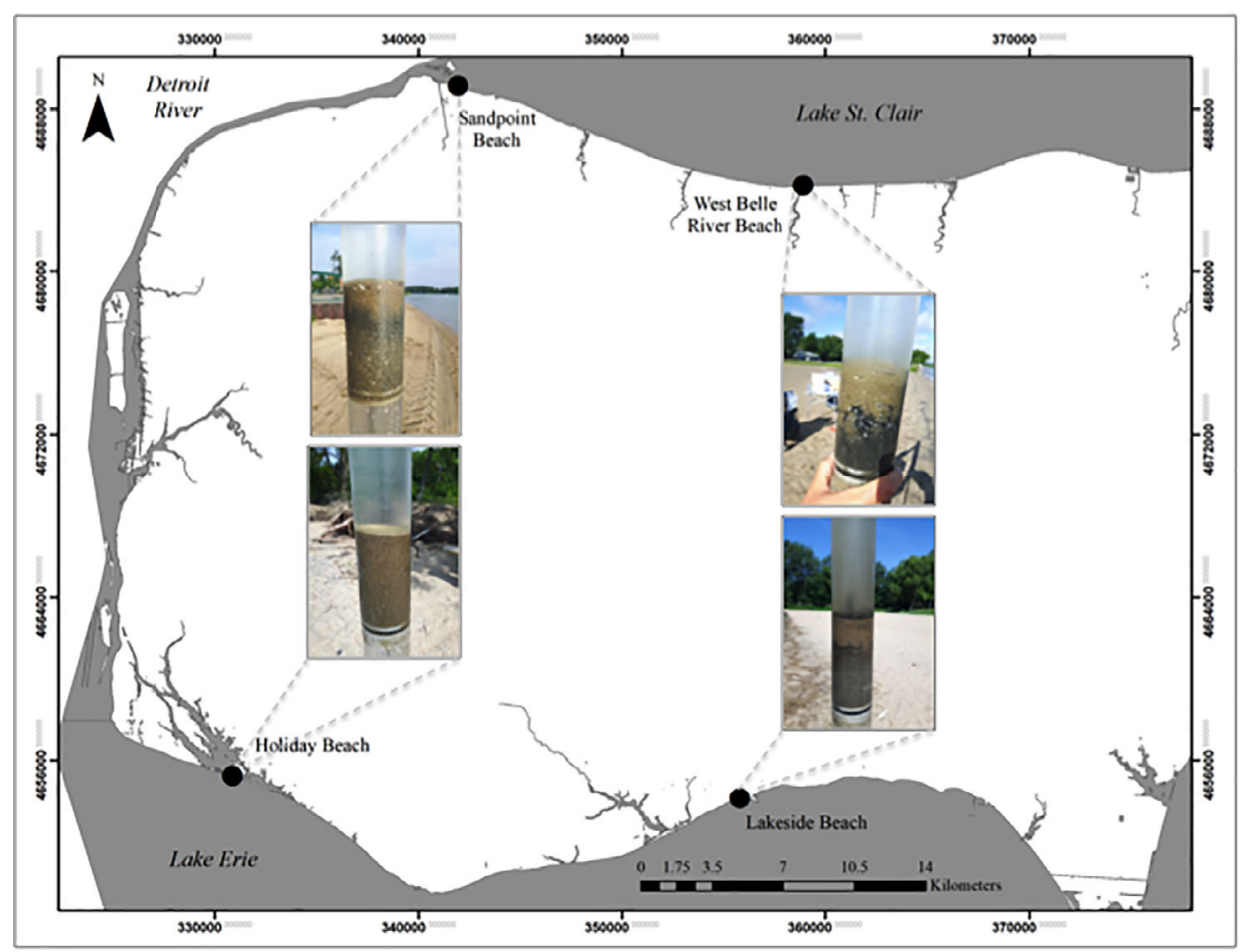

Fig. 1. Map of Windsor-Essex County; features displayed include Lake St. Clair, the Detroit River, Lake Erie and all four beaches sampled for this research. Photographs of sediment cores appear next to the representative location. [Color figure can be viewed at wileyonlinelibrary.com]

Table 1. Physicochemical conditions of the water column at Sandpoint (SP), Belle River (BR), Kingsville (KV), and Holiday (HD) beaches in WEC, Ontario.

\begin{tabular}{|c|c|c|c|c|c|c|c|c|c|c|c|}
\hline Beach & Depth (m) & $\begin{array}{l}\text { Temp. } \\
\left({ }^{\circ} \mathrm{C}\right)\end{array}$ & $\begin{array}{c}\mathrm{SPC} \\
\left(\mu \mathrm{S} \mathrm{cm}^{-1}\right)\end{array}$ & $\begin{array}{c}\text { TDS } \\
\left(\mathrm{mg} \mathrm{L}^{-1}\right)\end{array}$ & $\begin{array}{l}\text { Salinity } \\
\text { (psu) }\end{array}$ & ODO $\left(\mathrm{mg} \mathrm{L}^{-1}\right)$ & $\mathrm{pH}$ & ORP (mV) & $\begin{array}{l}\text { Turbidity } \\
\text { (NTU) }\end{array}$ & $\begin{array}{c}\mathrm{Chl} \mathrm{a} \\
\left(\mu \mathrm{g} \mathrm{L}^{-1}\right)\end{array}$ & $\begin{array}{r}\text { BGA-PC } \\
\left(\mu \mathrm{g} \mathrm{L}^{-1}\right)\end{array}$ \\
\hline SP & 0.58 & 26.1 & 237.1 & 154 & 0.11 & 7.97 & 8.4 & 103.4 & 4.77 & 0.79 & 0.42 \\
\hline BR & 0.44 & 23.7 & 229.5 & 149 & 0.11 & 9.03 & 8.44 & 110.1 & 31.24 & 4.77 & 1.21 \\
\hline $\mathrm{KV}$ & 0.13 & 25.6 & 490 & 319 & 0.23 & 11.55 & 8.6 & 119 & 55.82 & 53.45 & 3.89 \\
\hline HD & 0.59 & 25.8 & 250.8 & 163 & 0.12 & 7.17 & 8.04 & 114.7 & 34.99 & 6.08 & 1.11 \\
\hline
\end{tabular}

were averaged to represent their respective beach. Sequencing from the lon Torrent produced 295630 written sequences for the 16 samples, summarized in the Supporting Information Table S1. Sequence count per sample yielded 4462/ $64,640 / 18,476$ reads representing minimum/maximum/mean respectively. This data set clustered into 13134 bacterial OTUs at $97 \%$ sequence similarity.

Regarding the metatranscriptomic profiles derived from isolated mRNA, sequencing statistics for all samples

Table 2. Tabulated summary of physical properties characterizing each beach as high or low energy.

\begin{tabular}{lccccc}
\hline Beach & $\begin{array}{c}\text { Grain size, } \\
D_{50}(\mathrm{~mm})\end{array}$ & $\begin{array}{c}\text { Moisture } \\
(\%)\end{array}$ & $\begin{array}{c}\text { TOC } \\
(\% \text { LOI })\end{array}$ & Sheltered? & $\begin{array}{c}\text { High/low } \\
\text { energy }\end{array}$ \\
\hline SP & 0.65 & 18.31 & 0.83 & No & High \\
BR & 0.32 & 22.16 & 0.85 & Yes & Low \\
KV & 0.37 & 24.77 & 0.48 & Yes & Low \\
HD & 1.4 & 10.44 & 0.37 & No & High \\
\hline
\end{tabular}

obtained from the Illumina HiSeq 4000 run are summarized in the Supporting Information Table S2. Duplicates for each sample site are averaged. Altogether, the metatranscriptomics run resulted in 24-28 million reads for each beach. The sum of different identified functional annotations assigned through the KEGG database for each sample site all exceeded 550000 reads. To allow normalized comparisons between sites, expression levels are represented as a percentage relative to rpoC (DNA-directed RNA polymerase beta' subunit) from each sample.

\section{Taxonomic assessment}

Taxonomic surveys of the bed sediment at the four beaches showed Proteobacteria as the most abundant phylum in all locations, representing at least $30 \%$ of the community (Fig. 3A). Other top phyla include Bacteroidetes, Acidobacteria, Actinobacteria, Chloroflexi, Nitrospirae, and Firmicutes, all which have been extensively reported to 


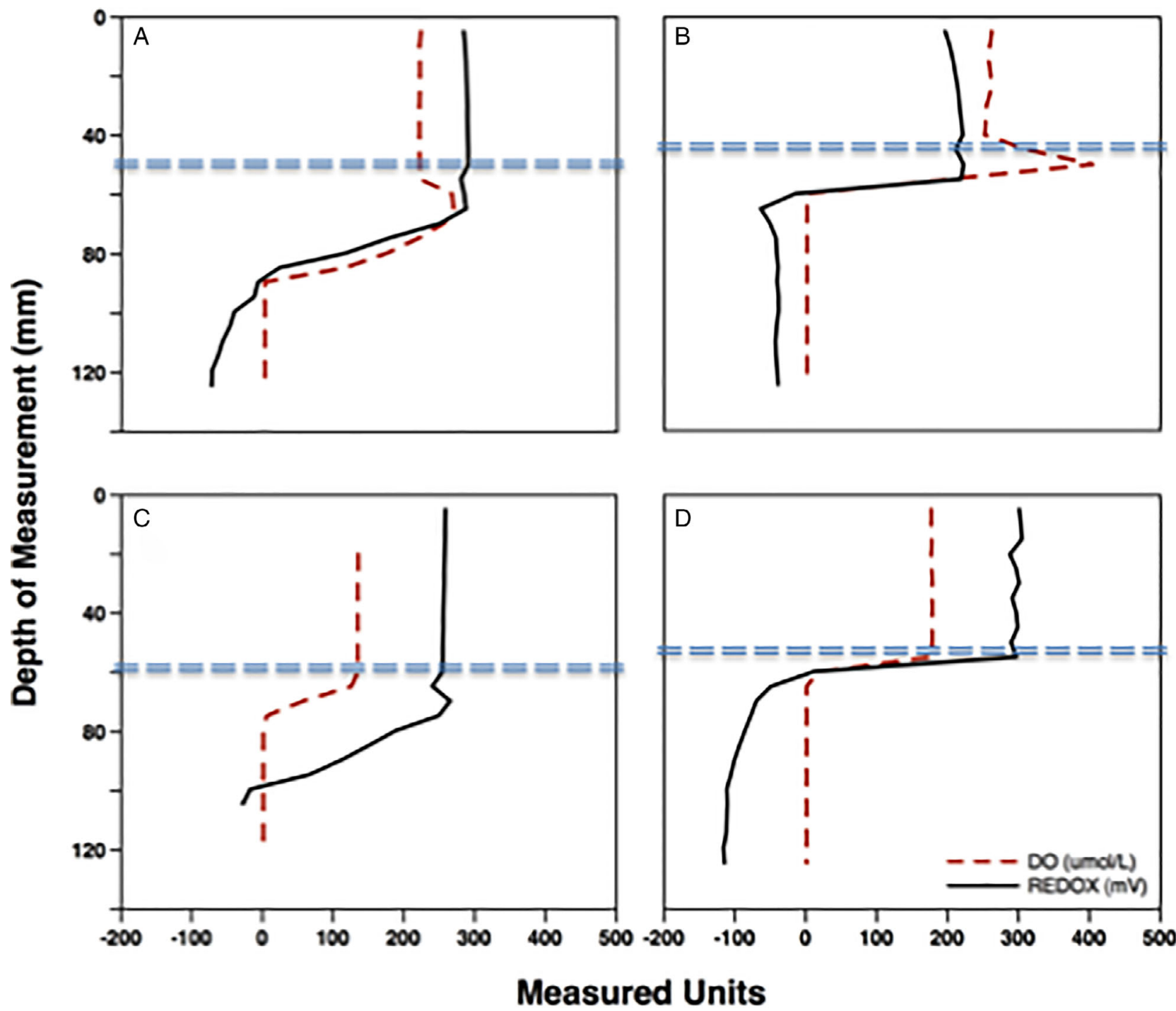

Fig. 2. Micro-sensor profiles of the bed sediment beach zone for (A) Sandpoint. B. Belle River. C. Holiday. D. Kingsville. Dissolved oxygen (DO) and redox measurements were obtained through the sediment-water interface of these zones. Double-dashed horizontal line represents the sediment-water interface, where above the line is in the water column and below is into the bed sediment. [Color figure can be viewed at wileyonlinelibrary.com]

inhabit sedimentary environments (Solo-Gabriele et al., 2016; Xie et al., 2016; Cheng et al., 2017). The relative abundance of major phyla and Proteobacteria classes appear to differ between the beach locations with no obvious trend relating to one lake system over the other. The exception pertains to BR and KV beaches, which showed a closer similarity to each other rather than to their same-lake beach counterpart. Perhaps, this is not surprising, however, since both BR and KV are similar physically and geochemically and represent beaches influenced by low-energy dynamics, as previously described (Tables 1 and 2).

Genus level investigation of the beach sediments identified some genera that comprise well-characterized native pathogenic organisms, including Escherichia-Shigella, Legionella, and Pseudomonas (Fig. 3B). These organisms have also been observed in previous studies as described by Whitman et al. (2014), which provides a detailed review of microbes in beach sands with a focus on human pathogens. Although it should be noted that (i) these organisms illustrate very low relative abundance $(<0.1 \%)$ and (ii) these data were determined solely on DNA extractions of the entire biomass and therefore cannot be considered a representation of the living microbial community. Regardless, it is still valuable information because it demonstrates that these types of organisms are capable of transport within these environments and may potentially be transmitted to people via recreational activities. Possible vectors for transport may be through (i) surface washoff of sediment via rain and snow melt, (ii) river bed sediment erosion (representing contemporary storage of pathogens mobilized 


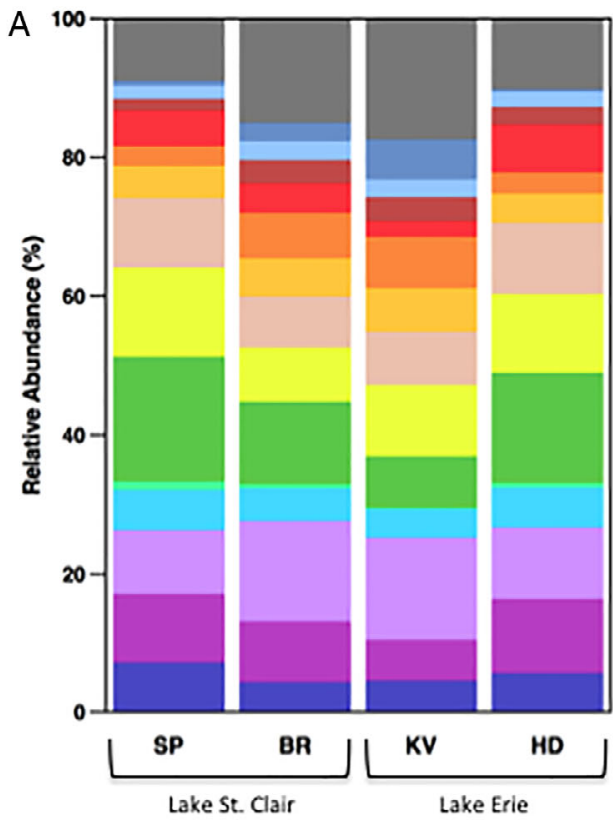

B

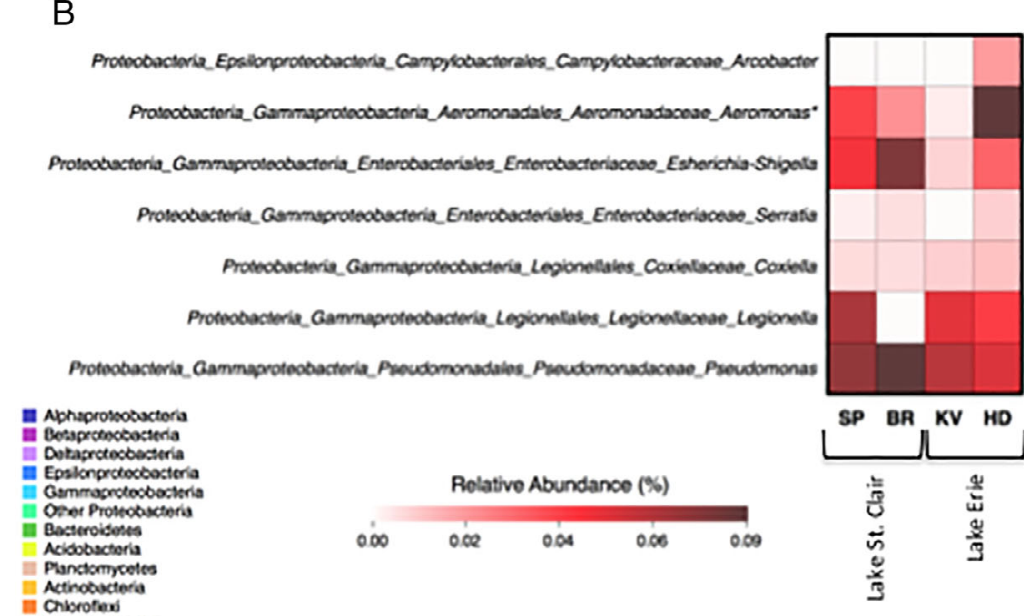

Fig. 3. Taxonomic survey of the bed sediment at the four freshwater beaches. A. Top abundant bacterial taxa of Sandpoint (SP), Belle River (BR), Kingsville (KV), and Holiday (HD) beaches. Note that phyla are represented for all groups except the Proteobacteria, which is broken down into its subsequent classes (Alpha-, Beta-, Delta-, Epsilon-, and Gamma-Proteobacteria). B. Heatmap illustrating the relative abundance of potential human bacterial pathogens (genus level) present at each sample location based on DNA isolation and 16S rRNA amplification. Note the small percentage values and the majority are members of the Gammaproteobacteria. * Includes cultured and uncultured spp. while others represent cultured taxa only. [Color figure can be viewed at wileyonlinelibrary.com]

with sufficient shear/flow), or (iii) possibly sourced directly from animals frequenting the beaches (i.e. gulls or dogs) (Edge and Hill, 2005; Droppo et al., 2009; Droppo et al., 2011; Cloutier and McLellan, 2017; Alm et al., 2018). Therefore, since there is evidence that these organisms can be isolated from the bed sediment in freshwater beaches, it is important to further investigate these communities and determine their level of functionality to evaluate their pathogenic potential through transcriptomic approaches.

\section{Transcriptomics and the active microbes}

Metatranscriptomics reveals overall gene expression. Metatranscriptomic analysis of our data set provided an extensive amount of functional annotations encoding genes from all functional categories recognized by the KO system (Fig. 4). Of all the characterized expressed transcripts ( 3 million combined) that document these beaches, we observe similar proportions between the four sites. However, two major functional categories appeared to be responsible for subtle variations between the two lake systems. When compared, Lake Erie sites illustrated higher proportion of posttranslational modification, protein turnover, chaperones, while Lake St. Clair showed higher percentage of energy production and conversion. Major variations such as water movement patterns and retention time at these beaches are the potential influencing factors for these differences in gene expression between lake samples. For instance, hydrological models (Anderson and Schwab, 2011; Niu and Xia, 2017) show considerably longer water retention times for the southern shoreline of Lake St. Clair (water age of 30 days; i.e. SP and BR) compared with northern Lake Erie shorelines in the Western Basin (i.e. HD and KV). This inherently may account for the increased energy production and conversion in Lake St. Clair samples since the sediment microbial community would presumably have longer time to utilize nutrients before being redistributed by long-shore drift. Regardless, these two categories combine to explain $28-33 \%$ of the entire characterized transcriptome for each site, suggesting that the microbial communities are growing and are metabolically active.

The dynamic nearshore hydrology associated with SP and HD illustrated the largest differences in both aforementioned functional categories; posttranslational modification, protein turnover, chaperones ( $9 \%$ at SP vs. $18 \%$ at $\mathrm{HD}$ ), and energy production and conversion (23\% at $\mathrm{SP}$ vs. $15 \%$ at $\mathrm{HD}$ ). These variances may reflect ecosystem adaptations to environmental differences such as the overlying water conditions (Table 1), variability in organic material (Table 2) or nutrient availability (Leimena et al., 2013). Benthic microorganisms may move through diverse environments throughout their life cycle within the lower water column and at the sediment-water interface, including those found in freshwater ecosystems, and 


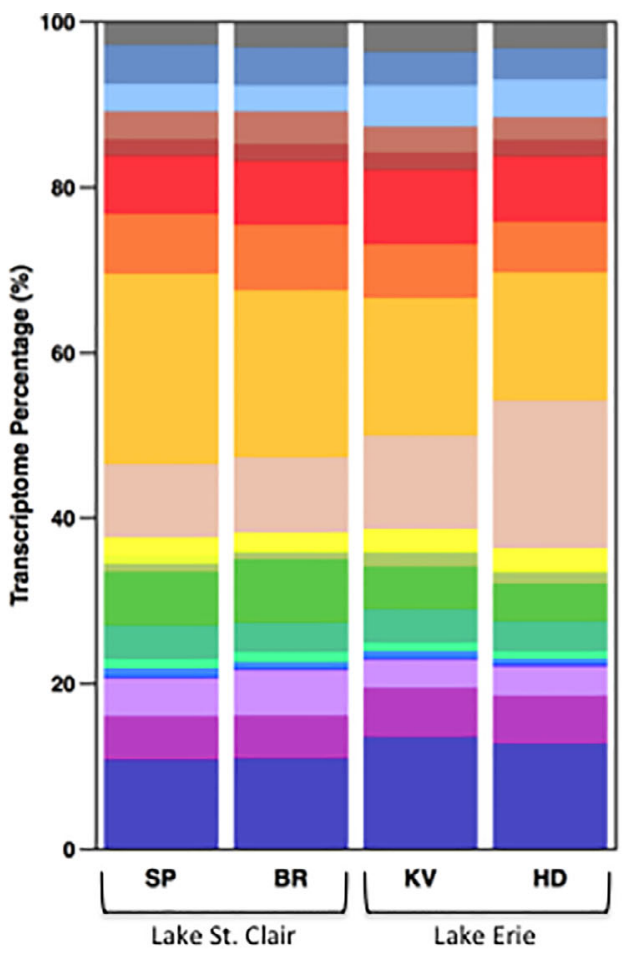

Fig. 4. Distribution of all wellcharacterized transcripts from the bed sediment into functional categories for the four freshwater beaches. [Color figure can be viewed at wileyonlinelibrary.com]
Translation, ribosomal structure and biogenesis

RNA processing and modification

- Transcription

Replication, recombinaton and repair

Chromatin structure and dynamics

Coll cyclo control, coll division, chromosome partitioning

Nudear structure

Dudear structure

Signal transocuction mechanisms

Signal transducton mechanisms

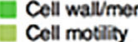

Cyloskeloton

Extracollular structures

Intracellular trafficking. secretion, and vesicular transport

Posttranslational modifcation, protein turnover, chaperones

Energy production and conversion

Carbohydrate transport and metabolism

Carbohydrato transport and metabolism

Amino acid transport and motabolism
Nudeotide transport and metabolism

Coenzyme transport and metabolism

Lipid transport and metabolism

Inorganic ion transport and metabolism

Socondary metabolites biosynthesis, transpont and catabolism viewed at wileyonlinelibrary.com]

\section{(1)}

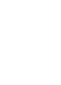




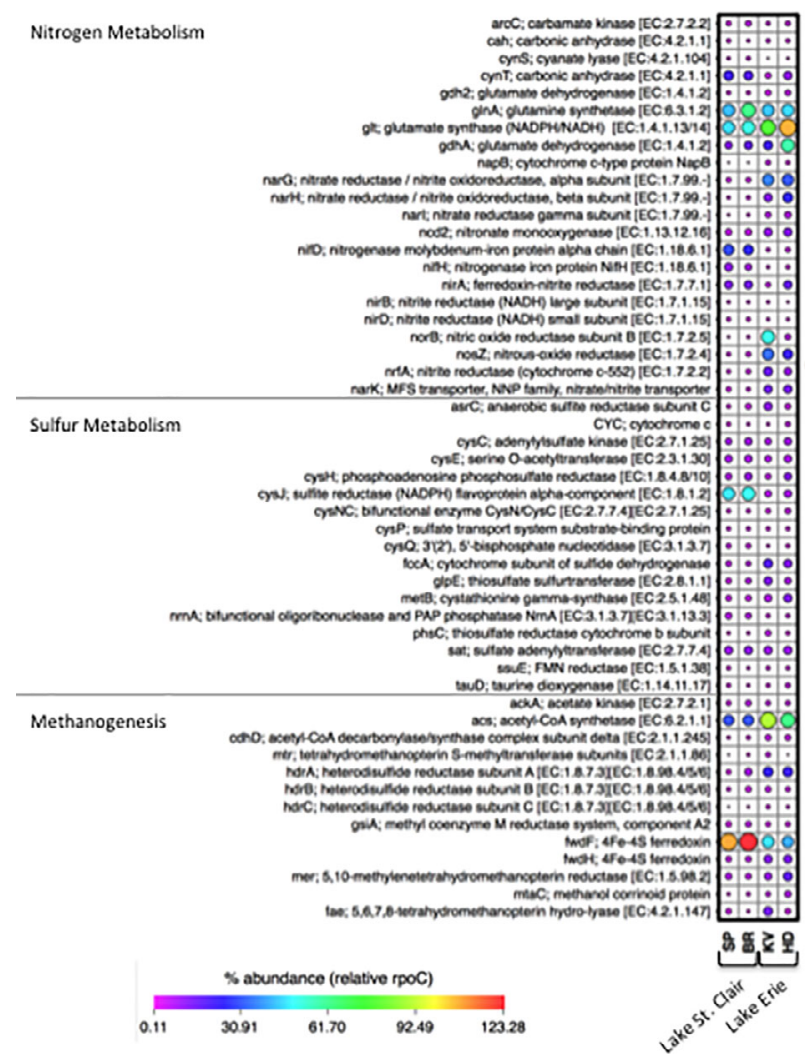

Fig. 5. Functional annotations assigned to transcripts involved in nitrogen metabolism, sulfur metabolism, and methanogenesis pathways within the top layer of bed sediment in four freshwater beaches. This heatmap uses colour range and proportional size scaling to allow for discernible comparisons. Expression is represented as percent abundance relative to rpoC gene. [Color figure can be viewed at wileyonlinelibrary.com]

subsurface environments tend to be influenced by denitrification mechanisms. Within this context, we highlight below the trends observed.

Comparison of $\mathrm{BR}$ and $\mathrm{KV}$ beaches in this study showed significantly $(p<0.05)$ different expression levels of transcripts encoding annotations belonging to $N$ cycling (Fig. 6). Expression of nar/napB and norB in KV showed $50 \%$ upregulation, and $30 \%$ upregulation for nosZ, all significantly differentially expressed compared with BR $(p<0.05)$. Denitrifying genes with high expression levels such as these at KV are comparable to sediment sampled at a discharge zone of a local wastewater treatment plant (Weisener et al., 2017). Because there is such high expression for denitrification suggests that excessive amounts of bioavailable nitrate are present at $\mathrm{KV}$ beach for microbial utilization. This nitrate could potentially be sourced from either faecal contamination (i.e. wildlife excrement) or high levels of fertilizer runoff from agricultural or residential landscapes that deposits in these low-energy shorelines (Melton et al., 2014; Weisener et al., 2017). On the other hand, BR showed higher expression of transcripts encoding for assimilatory nitrate reduction to ammonia, ANRA (nirA; 15\% at BR vs. $4 \%$ at $\mathrm{KV}$ ) and $\mathrm{N}$ fixation (nifDH; $33 \%$ at $\mathrm{BR}$ vs. $3 \%$ at $\mathrm{KV}$ ), both pathways leading to the production of ammonia. Biological $\mathrm{N}$ fixation is an essential function of microorganisms because fixed inorganic $\mathrm{N}$ compounds are required for biosynthesis of organic compounds and cellular survival (Wang et al., 2016). If bioavailable $\mathrm{N}$ species (such as nitrate) are not at sufficient concentrations, microbes will fix atmospheric $\mathrm{N}$ to acquire this essential nutrient (Salk et al., 2018). In this case, a large number of characterized nitrogen-fixing bacteria in soils belong to the Alphaproteobacteria (Tsoy et al., 2016), which are represented at all four beaches with relative abundance of $4-7 \%$ (Fig. 3A). We identified much higher expression of nifDH at $\mathrm{BR}$ compared with $\mathrm{KV}$, suggesting that $\mathrm{BR}$ contained low bioavailable $\mathrm{N}$, resulting in the microbial community to rely on $\mathrm{N}$ fixation to supply a sufficient amount of bioavailable $\mathrm{N}$ for essential cellular processes. This, in turn, highlights the contrasting chemical characteristics of these two locations with respect to nutrient content.

Key differences in $\mathrm{N}$ metabolism exist between the two beaches/lake environments. The microbial community associated with Lake Erie shorelines appears influenced by respiratory and detoxification strategies, while Lake St. Clair shorelines have developed metabolisms that are energy focused (e.g. biosynthesis and primary production). In some context, this is understandable because there exists long hydraulic residence times along the Lake St. Clair southern shore thus creating a stable physical environment in which primary producers can flourish (Michalak et al., 2013). It is worth noting that $\mathrm{KV}$ demonstrated the highest $\mathrm{Chl}$ concentrations $\left(53.45 \mu \mathrm{g} \mathrm{L}^{-1}\right)$ of all sites, while $\mathrm{BR}$ reported much less in comparison $\left(4.77 \mu \mathrm{g} \mathrm{L}^{-1}\right.$; Table 1). However, these values reflect planktonic communities and may not represent biofilm established on/within the sediment surface. In fact, taxonomic results showed the relative abundance of Cyanobacteria at $\mathrm{BR}(0.68 \%)$ was six times greater than at KV $(0.11 \%)$. Furthermore, a sharp spike in DO was recorded at BR immediately below the sediment-water interface (Fig. 2B), adding more evidence of phototrophic biofilm activity on the bed sediment.

Significance of bacterial survival and the influence of nitric oxide. Expression of bacterial transcripts encoding $\mathrm{N}$ metabolism demonstrated specialized mechanisms employed by the bacteria for metabolizing/detoxifying nitric oxide (Fig. 7). Nitric oxide (NO) is a toxic, intermediate molecule of the $\mathrm{N}$ cycle and organisms employ diverse systems to defend against (and/or utilize) its harmful effects (Poole, 2005). Bacteria, including pathogens, have evolved unique mechanisms for NO detoxification in order to survive and succeed in their environment (Gardner et al., 2002; Gilberthorpe and 


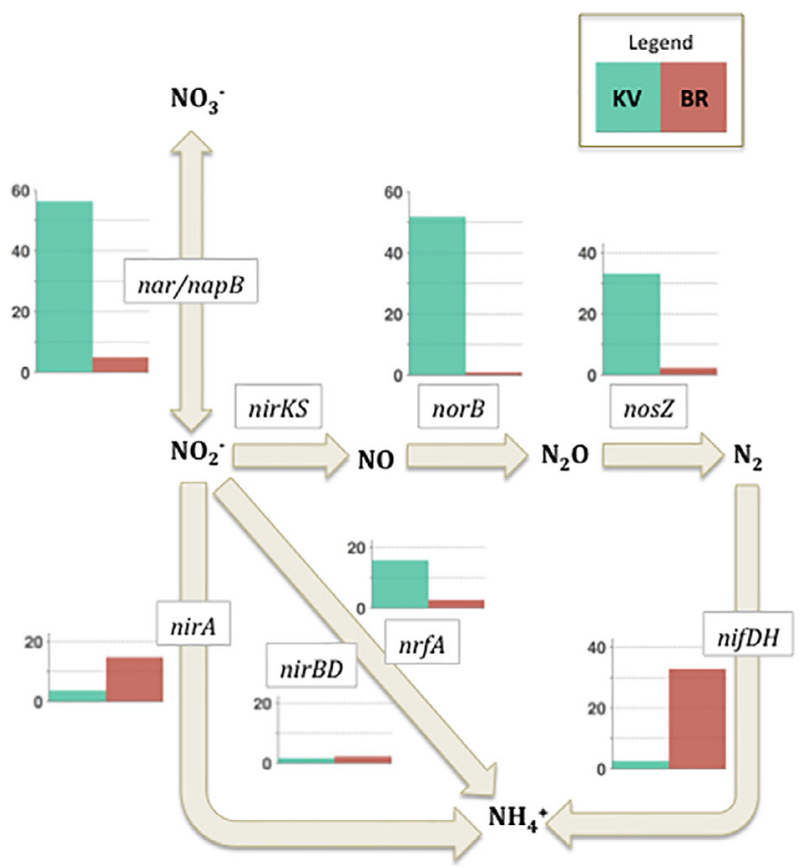

Fig. 6. Expression of nitrogen metabolism genes involved in denitrification, dissimilatory and assimilatory nitrate reduction, and nitrogen fixation within the nearshore bed sediment of Kingsville (KV) and Belle River (BR) public beaches. Expression is represented as percent abundance relative to rpoC gene. [Color figure can be viewed at wileyonlinelibrary.com]

Poole, 2008; Spiro, 2012). Enterobacteria, for example, possess several NO-detoxifying mechanisms, the most prominent being the flavohemoglobin Hmp and the flavorubredoxin NorV (Poole, 2005; Gilberthorpe and Poole, 2008). Also, cytochrome $c$ nitrite reductases (NrfA) are present in the periplasm of Gram-negative bacteria, which reduce nitrite directly to ammonia, bypassing production of NO altogether (Mohan et al., 2004). Genomic analysis of many pathogenic enteric bacteria reveals the presence of $n r f$ genes as it plays an important role in NO management in oxygen-limited environments (Poock et al., 2002). In our data set (Fig. 7), expression of norV at BR (41.74\%) is strongly upregulated compared with $\mathrm{KV}(11.38 \%)$, while nrfA shows greater expression at KV (15.73\%) than BR (2.72\%). Regarding $h m p$, expression at either beach is low $(<0.15 \%)$, yet is expressed nonetheless.

The transcriptional regulator NsrR has gained attention in recent years because of its suggested key role in controlling the complete perplasmic bacterial stress response to NO (Bodenmiller and Spiro, 2006; Filenko et al., 2007). Tucker et al. (2010) demonstrated that NO directly affects the Fe-S cluster of NsrR, which is responsible for controlling the transcription of NO-detoxifying genes (i.e. $h m p$ and $n r f A)$. Furthermore, it has been shown that these aforementioned enzymes constitute a cooperative network in pathogenic bacteria to detoxify NO (Fig. 8; Rodionov et al., 2005; Bodenmiller and Spiro, 2006; Gilberthorpe and Poole, 2008; Tucker et al., 2010). Our results show transcription of several NO-reducing genes in both BR and $\mathrm{KV}$ yet no expression of $n s r R$. This suggests that $\mathrm{NO}$ is present in these beaches, but also that the bacteria are actively metabolizing it for their survival, which may include those with pathogenic capabilities.

Examining $\mathrm{N}$ metabolism and genes involved in $\mathrm{N}$ cycling, especially NO detoxification, aid in discerning how bacterial pathogens are able to adapt to hazardous environments and ultimately survive (Gardner et al., 2002; Gilberthorpe and Poole, 2008; Spiro, 2012). Expression of transcripts encoding pathogenicity and infectious diseases, however, portray the diverse risk associated with recreational water usage in freshwater systems.

\section{Expression of genes encoding pathogenicity}

- Signatures of Salmonella infection. In our study, the direct link to pathogenic potential comes from the expression of virulence factors detected in the beach sediments (Fig.7 and 8). Here, we detected expression of the transcript encoding the secreted effector protein pipB2 at BR $(39.83 \%)$ as well as KV (2.51\%). Additionally, the Salmonella virulence factor $\mathrm{sspH} 2$ also demonstrated expression at both of these beaches, with $3.35 \%$ at BR and $2.28 \%$ at $\mathrm{KV}$.

These pathogen-related genetic factors have been reported to play active roles involved in modifying the host cytoskeleton (SspH2; Miao et al., 2003; Bakowski et al., 2008; Haraga et al., 2008), and pathogen replication (PipB2; Henry et al., 2006; Szeto et al., 2009). Reports on these genes, however, are typically associated with medical microbiology not environmental systems; Salmonella pathogens are not commonly believed to survive in beach environments, much less the source of these organisms is not well understood (Pandey et al., 2014). Biological contaminants are typically introduced into aquatic ecosystems by surface and subsurface runoff, wastewater and agricultural discharge, or avian/animal excrement (Field and Samadpour, 2007; Ksoll et al., 2007). Additionally, more recent environmental studies have provided evidence for bacterial pathogen survival in natural environments. For example, in the Great Lakes, it has been reported that aquatic vegetation (i.e. green alga Cladophora) can serve as an environmental reservoir for bacterial pathogens such as Salmonella thus improving their chances of survival in beach environments (Ishii et al. 2006; Byappanahalli et al. 2009). Based on this, it is possible that beachgoers may be exposed to these enteric pathogens during recreational activities.

Our data, combined with the expression data of the NO-detoxification transcripts, suggest that pathogenic organisms were present and active in these beach bed sediments at the time of sampling. However, contrary to the taxonomic analysis (Fig. 3B), the transcriptomic data 


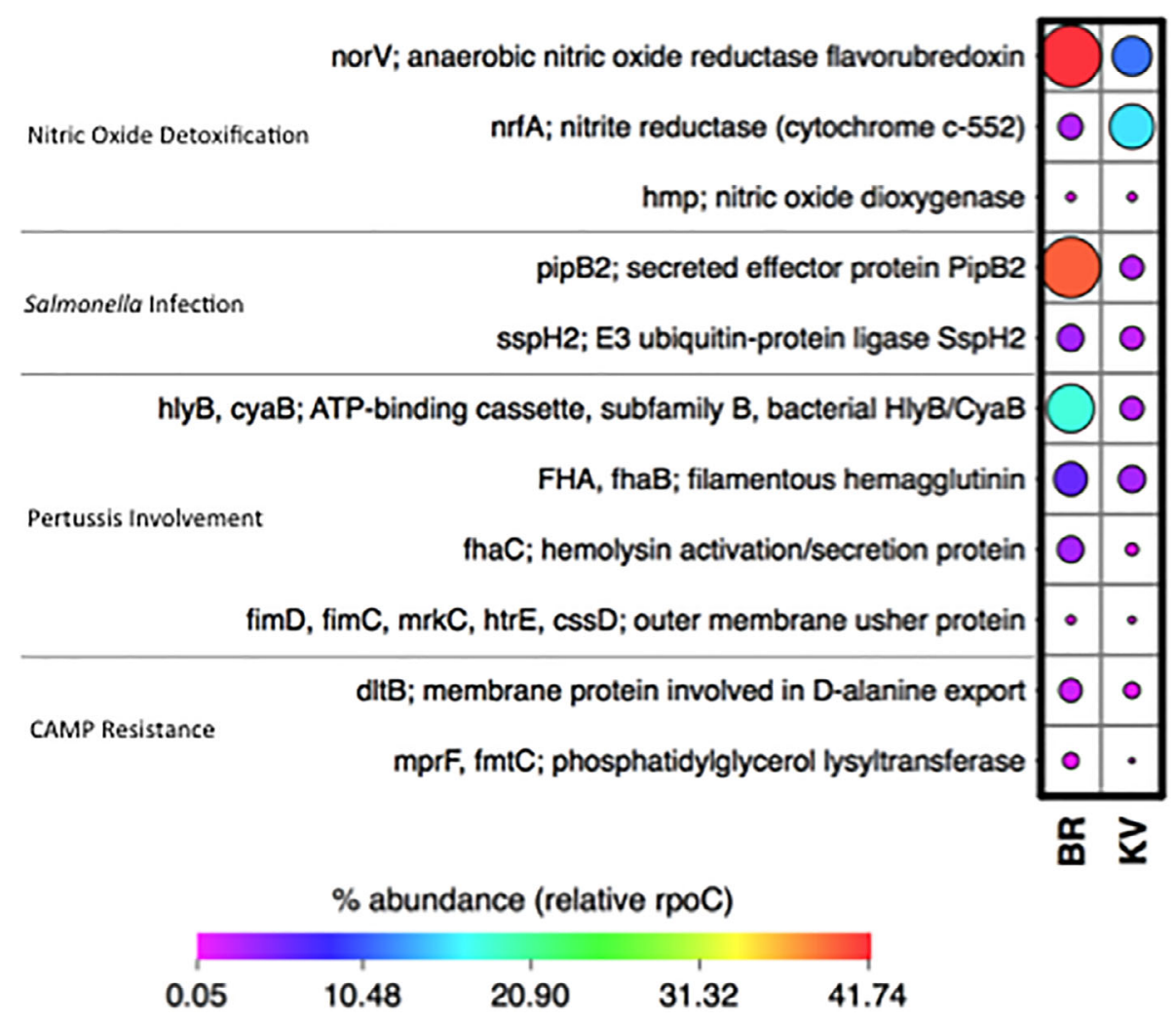

Fig. 7. Expression of transcripts with pathogenic relevance from the bed sediment beach samples at Belle River (BR) and Kingsville (KV) beaches. Expression is represented as percent abundance relative to $r p o C$ gene. [Color figure can be viewed at wileyonlinelibrary.com] specifically revealed expression of genes involved with Salmonella pathogenicity. A plausible explanation for this could be horizontal gene transfer (HGT) in these environments and may be the underlying mechanism for gene acquisition by other organisms (Molin and Tolker-Nielsen, 2003; Madsen et al., 2012; Heß et al., 2018). This consideration helps support the proposal that taxonomic surveys alone perhaps do not capture the underlying pathogenic potential of a system; this is especially important when considering human health risks at public beaches for recreation water use.

- Expression of genes involved in pertussis. Pertussis (aka whooping cough) is a highly contagious respiratory disease that affects humans (de Gouw et al., 2011). Although Bordetella pertussis, the aetiological agent of the disease, is not a known waterborne pathogen and has not been reported in environmental samples, expression of transcripts encoding for genes involved in the disease were identified in our samples (Figs. 7 and 8). Other Bordetella spp. have been detected in environmental samples (e.g. sediment, water) and there is recent belief that this genus is of environmental origin (Soumana et al., 2017).

Consistently, the highest expression of transcripts in this list (Fig. 7) belonged to BR. The ATP-binding cassette, $h l y B / c y a B$, showed highest expression at BR with $17.96 \%$, and $2.55 \%$ at $\mathrm{KV}$. These are homologous transporter proteins that are required for secretion of virulence factors (Zaitseva et al., 2005). One virulence factor of pertussis is filamentous hemagglutinin, FhaB/FHA (Melvin et al., 2015), which plays an important role in the adhesion of virulent organisms to the respiratory tract of the host (Locht et al., 1993). Translocation of this protein across the outer membrane of $B$. pertussis requires the secretion protein FhaC (Mazar and Cotter, 2006; Noël et al., 2012; Melvin et al., 2015). Expression of fhaB and fhaC was detected in both beach sediments, with $B R$ showing higher expression $(6.04 \%$ and $3.41 \%$ ) compared with $\mathrm{KV}(3.44 \%$ and $0.48 \%)$ respectively.

Fimbriae also function as critically important mediators of adherence for many Gram-negative bacterial pathogens (Remaut et al., 2008) and are recognized as a primary mechanism of virulence (Connell et al., 1996). Although there was no expression of transcripts encoding fimbrial proteins in our data set, there was expression of the outer membrane usher protein (FimD)/periplasmic chaperone (FimC) in both BR (0.14\%) and KV $(0.09 \%)$, demonstrating functional gene expression related to pertussis. Again, this contradicts our taxonomy data since Bordetella was not represented (Fig. 3B) yet perhaps can be explained by HGT in these subsurface environments.

- Expression of other (pathogenic) transcripts. In both locations, we report expression of two different genes with cationic antimicrobial peptide (CAMP) resistance functionality, an important characteristic of pathogenic 


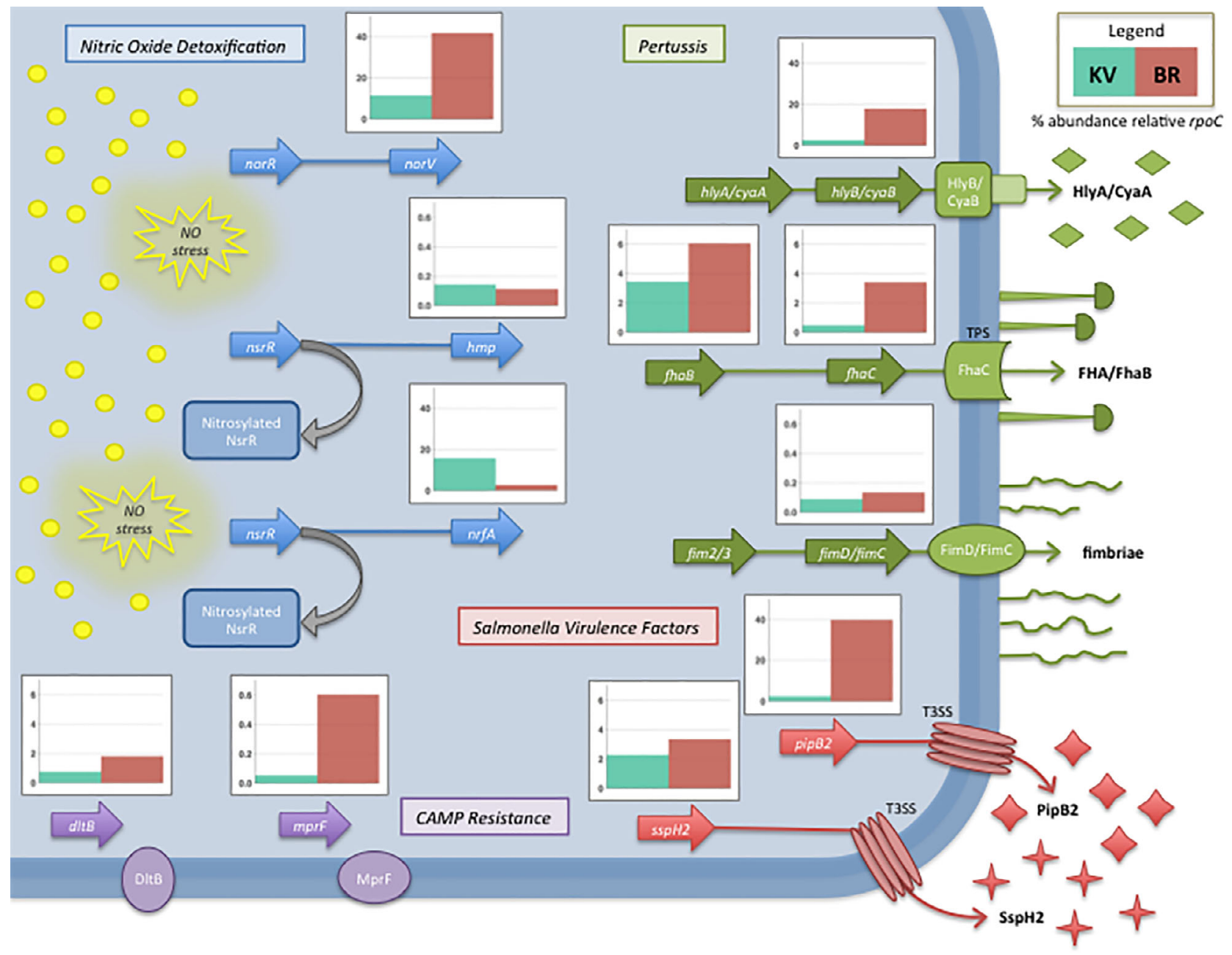

Fig. 8. Proposed universal bacterial pathogen. Schematic of genes involved in nitric oxide detoxification (blue), CAMP resistance (purple), Salmonella infection (red), and pertussis (green). Expression of functional annotations encoding illustrated transcripts appears directly above stated gene. Yellow circles represent nitric oxide. Salmonella virulence factors are translocated out of the pathogen through a type III secretion system (T3SS). Translocation of FHA/FhaB protein is through a two-partner secretion (TPS) system, which requires the secretion protein FhaC. Note there are three different $\mathrm{y}$-axis scales (0-40\%; 0-6\%; 0.0-0.6\%), used to clearly illustrate expression levels and comparisons between $\mathrm{KV}$ and $\mathrm{BR}$. Expression of transcripts is represented as percentage relative to the housekeeping gene, rpoC. [Color figure can be viewed at wileyonlinelibrary.com]

organisms to colonize their host (Peschel et al., 1999; Peschel et al., 2001; Joo et al., 2016). DltB and MprF are both membrane proteins specific to Gram-positive bacteria and catalyse similar reactions (Li et al., 2007). The phosphatidylglycerol lysyltransferase, $m p r F$, showed $0.60 \%$ expression in BR beach bed sediment and $0.05 \%$ expression at KV. Expression of membrane protein transcript $d / t B$ was also more highly expressed at $\mathrm{BR}(1.82 \%)$ than $\mathrm{KV}(0.75 \%)$. These data are important to consider because antibiotic resistant bacteria (ARB) are a serious threat to human health and treating bacterial infections is becoming increasingly more challenging due to antimicrobial resistant genes (ARGs). Additionally, the evolution and spread of ARB and ARG is not well understood, especially when considering the natural environment (Leonard et al., 2015).

\section{Environmental implications}

Water quality assessments of public beaches have traditionally focused on simplistic evaluations concentrated on taxonomic surveys within the water column only and neglect to incorporate the interconnection of the physical and geochemical characteristics to these microbial evaluations (Heaney et al., 2009; Heaney et al., 2012). However, the water and sediment compartments are perpetually linked as they influence each other in their dynamic setting, and it has been argued that sediment may have stronger association with microbial life than the planktonic counterpart (Droppo et al., 2011; Probandt et al., 2018). Our observations of expressed transcripts associated with non-waterborne pathogens present in beach environments is evidence of the possible transport 
of these pathogens from the terrestrial to the aquatic system by attachment to sediment particles.

In our present study, we investigated the microbial community structure and function of bed sediment at freshwater beaches and, together with the physicochemical analysis of the sediment and surrounding water characteristics, we are able to evaluate location properties as an improved means for determining the safety of public beaches for recreational use. As other studies have reported, freshwater beach sands can be considered a reservoir of bacterial pathogens (Sousa et al., 2015; Mohiuddin et al., 2017), and smaller particle sizes of these sediments are associated with persistence of FIB (Zimmer-Faust et al., 2017). Both BR and KV beaches are representative of low-energy environments with tightly packed small sediment particles restricting diffusion of DO with depth (Fig. 2). These physical features are indicative of higher potential for increased microbial persistence and activity, including bacterial pathogens, as we have shown in this work. As such, these types of locations may potentially have a higher risk related to aquatic and human health.

Through HGT, microorganisms can acquire specialized functions for a multitude of activities, including pathogenicity (Molin and Tolker-Nielsen, 2003). Moreover, HGT potential is increased in densely populated locations, such as biofilms and sedimentary environments (Madsen et al., 2012). This supports the fact that taxonomic surveys alone cannot determine the true pathogenic potential of a system and are an out-dated means for public beach evaluations. Our research validates this as gene expression data of our beach sediments revealed pathogenic potential typical of particular organisms (e.g. Salmonella and Bordetella; Figs. 7 and 8), yet our taxonomy assessment did not identify the aetiological taxa (Fig. 3). For these reasons, we introduce a proposed universal bacterial pathogen model (Fig. 8), which considers the combined and synergistic processes used by microbes that may acquire these functions by HGT in these densely populated and physically dynamic subsurface systems.

\section{Conclusions}

Energy metabolism and nutrient cycling are functional processes that can be analysed in situ to better characterize the active microbial community in environmental samples. Insight into these functions helps us understand the overall biogeochemistry of a system and can lead to underlying mechanisms of additional microbial lifestyles, such as pathogen survival and persistence. Although our transcriptomic sediment observations here share characteristics similar to those most observed in clinical trials and research, we were able to demonstrate clear evidence of bacterial pathogenic potential in the selected freshwater beach sediments through gene expression data. This information significantly contributes to our current understanding of human health risks regarding recreational water use and provides valuable insight into the true potential biohazards that should be considered by management and policy makers when evaluating the status of public beaches.

While this study did not investigate the level of gene expression required to induce infection or lead to toxicity effects, it is the first to provide transcriptomic evidence of bacterial pathogenic gene expression within the bed sediment of freshwater beach environments. This information allowed us to evaluate location characteristics in relation to the microbiota and can lead to predictive inference at other freshwater beaches to evaluate their likelihood of posing human health risks. Often this type of information is typically overlooked since most research investigates taxonomic surveys or is focused within the water compartment only. Furthermore, we illustrated evidence of pathogens other than $E$. coli, highlighting the fact that these ecosystems can harbour more human health concerns than what is currently being portrayed through traditional water quality assessments. We also considered HGT as a viable avenue for pathogenic gene acquisition in these densely microbial-populated environments, further supporting the idea that simplistic taxonomic surveys of the water column are out-dated and unreliable for determining the bacterial health risks of public beaches. Finally, we propose a multifaceted assessment of beach systems that includes sediment characteristics and biogeochemical evaluations in addition to pathogenic gene expression of the nearshore subsurface environment. With this approach, we can build a comprehensive database of biogeochemical properties of these systems to help guide predictive assessments at problematic beaches.

\section{Experimental procedures}

\section{Site selection, characteristics and sediment sampling}

WEC is strongly recognized for its vast and successful agricultural land use, including livestock farms as well as high crop yields through conventional farming and greenhouse productions. WECHU subjects public beaches to weekly water quality testing each year from June through September, reporting on indicator $E$. coli CFUs as well as the status of the beach (i.e. open, caution, closed) based on these findings (www.wechu.org).

Sampling was conducted within $24 \mathrm{~h}$; Lake Erie locations (HD and KV) on 7 July 2016 and Lake St. Clair locations (SP and BR) on 8 July 2016. These sampling dates were during peak summer temperatures and consequently, high recreational water usage. Additionally, this sampling week reflects some of the highest $E$. coli 
counts of the 2016 season in WEC public beaches according to WECHU data. Sediment samples were collected through a gravity coring technique within the nearshore (i.e. ankle- to waist-deep water) to access sediment below the water column with minimal disturbance. Surface sediment was collected from the cores using sterile scoops and collected in sterile $5 \mathrm{~mL}$ cryogenic vials, flash frozen in liquid nitrogen, and transported in a Molecular Dimensions Dry Shipper (CX100). Once in the laboratory, samples were stored at $-80^{\circ} \mathrm{C}$ until extractions were performed (Rissanen et al., 2010).

Sediment granulometry was determined by sieving dried $\left(\sim 8 \mathrm{~h}\right.$ at $\left.50^{\circ} \mathrm{C}\right)$, bulk bed sediment from the upper layer within the nearshore swim zone. Eight sieves were utilized for grain size characterization, ranging from 63 to $2000 \mu \mathrm{m}$. Sediment moisture content was determined by mass before and after drying. Total organic carbon (TOC) was assessed by loss-on-ignition (LOI) (Bojko and Kabala, 2014) on bulk bed sediment from the upper layer as well. Beaches were designated as either sheltered (low energy) or not sheltered (high energy) based on observation of restricted water flow due to adjacent piers, degree of embayment, and observed wave heights over the duration of site visits over a 2 year period.

In situ electrochemical measurements across the sediment-water interface were obtained from microelectrode sensors (Unisense) controlled using the autonomous Unisense MiniProfiler MP4 shallow water field profiling unit. It was pre-programmed for precise, controlled deployment of sensors across a desired distance to obtain depth profiles of dissolved oxygen (DO) and electrochemical potential (redox). Water column parameters [depth, temperature, conductivity (SPC), total dissolved solids (TDS), salinity, DO, pH, oxidizing-reducing potential (ORP), turbidity, chlorophyll a ( $\mathrm{Chl}$ a), and phycocyanin (BGA-PC)] were measured using the EXO2 sonde with calibrated sensors (Hoskin Scientific) in the nearshore proximal to sediment sample collection but prior to sediment coring to avoid subsequent bed disturbances and resuspension.

\section{Extractions, library preparation, quality control and sequencing}

Sediment DNA extractions were performed using PowerSoil Total DNA Isolation kits (MoBio) following the manufacturer's instructions. DNA libraries were developed using a two-stage PCR approach and amplicon product purification was accomplished with SPRI beads (details in the Supporting Information; Vo and Jedlicka, 2014; VanMensel et al., 2017).

Sediment RNA extractions were performed using PowerSoil Total RNA Isolation kits (MoBio) following the manufacturer's protocol with slight modifications. Sample weight was increased from $2 \mathrm{~g}$ to $5 \mathrm{~g}$, and extractions began with sediment still in a semi-frozen state to minimize RNA degradation. DNase/RNase-free reagents, tubes and pipet tips were kept chilled on ice when practical; exceptions include reagents that required room temperature (to avoid precipitation) and sample transfers. RNA precipitation was extended to $>12 \mathrm{~h}$ at $-20^{\circ} \mathrm{C}$ to increase yield, and the final pellet was resuspended in $60 \mu \mathrm{L}$ RNase-free water to increase concentration. Aliquots of extracted RNA isolations were kept at $-80^{\circ} \mathrm{C}$ until further processing. Quality and quantity of extracted RNA samples were assessed in-house using the Agilent 2100 Bioanalyzer (Agilent Technologies) to confirm sufficient values for sequencing. Samples with RNA integrity num-

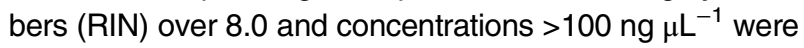
acceptable and sent to the Genome Quebec Innovation Center at McGill University in Quebec, Canada for metatranscriptomic analysis (see details in the Supporting Information). Samples were sequenced in duplicate to validate sample accuracy.

Raw sequence data sets for both 16S rRNA and metatranscriptomic data have been deposited in the Sequence Read Archive (http://www.ncbi.nlm.nih.gov/sra) under PRJNA482773.

\section{Bioinformatic analysis}

Taxonomic analysis of the bacterial community was performed on DNA data using MacQIIME (Quantitative Insights Into Microbial Taxonomy), an open-source bioinformatics pipeline (http://qiime.org/). Submitted sequences were assigned into operational taxonomic units (OTUs) using open-reference OTU picking at $97 \%$ similarity, and taxonomy was assigned based on the SILVA database (Pruesse et al., 2007; Yilmaz et al., 2014). Cumulativesum scaling (CSS) normalization was applied to account for uneven sample reads and allow for acceptable comparisons (Paulson et al., 2013).

The open-source pipeline MetaTrans (Martinez et al., 2016) was used to analyse the functionality of the active microbial communities from our mRNA samples. From the Illumina platform, we obtained paired-end reads in fastq format (Phred +33) separated into individual files for each single-end read. Raw reads were filtered using the Kraken pipeline (Davis et al., 2013; Wood and Salzberg, 2014) and reads with length less than $30 \mathrm{nt}$ were removed. mRNA was sorted from rRNA/tRNA using SortMeRNA (Kopylova et al., 2012). To recover a functional profile for each sample, mRNA reads were mapped against the M5nr database (Wilke et al., 2015), and differentially expressed functions were determined through the DESeq2 package (Love et al., 2014). All functional annotations were assigned using the KO [Kyoto Encyclopedia of Genes and Genomes (KEGG) Orthology] database, and those that were assigned to 
recognized functional groups were normalized within each sample to housekeeping gene rpoC (DNA-directed RNA polymerase beta' subunit; Nieto et al., 2009; Colston et al., 2014). Transcripts that were not recognized or encoded for poorly characterized functions were excluded from further analysis. The entire transcriptome was obtained through this approach, which allowed for a full overview of the microbial activity within these bed sediments. However, we did ultimately narrow our results to focus on those involved, either directly or indirectly, with infectious diseases and pathogenicity. Pathogenic gene selection was determined through the KEGG database, targeting functional annotations under Infectious Diseases. Functional assignments were interpreted and plotted within Aabel 3 graphical software to present visualizations of the represented data.

\section{Acknowledgements}

The authors would like to thank Shelby Mackie in the Environmental Genomics Facility (EGF) and Courtney Spencer at the Great Lakes Institute for Environmental Research (GLIER), University of Windsor. The authors acknowledge the Genome Quebec Innovation Center at McGill University in Quebec, Canada for metatranscriptomic analysis. We express thanks for funding support for this project from NSERC Strategic Partnerships Program entitled 'Great Lakes Water Security: Microbial community characterization, source tracking, and remediation through meta-genomics' REF341061127. Finally, the authors thank their anonymous reviewers for their constructive feedback, which helped us to revise this manuscript.

\section{References}

Alm, E.W., Burke, J., and Spain, A. (2003) Fecal indicator bacteria are abundant in wet sand at freshwater beaches. Water Res 37: 3978-3982.

Alm, E.W., Daniels-Witt, Q.R., Learman, D.R., Ryu, H., Jordan, D.W., Gehring, T.M., and Domingo, J.S. (2018) Potential for gulls to transport bacteria from human waste sites to beaches. Sci Total Environ 615: 123-130.

Anderson, E.J., and Schwab, D.J. (2011) Relationships between wind-driven and hydraulic flow in Lake St. Clair and the St. Clair River Delta. J Great Lakes Res 37: 147-158.

Bakowski, M.A., Braun, V., and Brumell, J.H. (2008) Salmonella-containing vacuoles: directed traffic and nesting to grow. Traffic 9: 2022-2031.

Beversdorf, L.J., Bornstein-Forst, S.M., and McLellan, S.L. (2007) The potential for beach sand to serve as a reservoir for Escherichia coli and the physical influences on cell die-off. J Appl Microbiol 102: 1372-1381.

Bodenmiller, D.M., and Spiro, S. (2006) The yjeB (nsrR) gene of Escherichia coli encodes a nitric oxide-sensitive transcriptional regulator. J Bacteriol 188: 874-881.

Bojko, O., and Kabala, C. (2014) Loss-on-ignition as an estimate of total organic carbon in the mountain soils. Soil Chem 47: 71-79.
Byappanahalli, M.A., Sawdey, R., Ishii, S., Shively, D.A., Ferguson, J.A., Whitman, R.L., and Sadowsky, M.J. (2009) Seasonal stability of Cladophora associated Salmonella in Lake Michigan watersheds. Water Res 439: 806-814.

Chen, M., Walshe, G., Chi Fru, E., Ciborowski, J.J.H., and Weisener, C.G. (2013) Microcosm assessment of the biogeochemical development of sulfur and oxygen in oil sands fluid fine tailings. Appl Geochem 37: 1-11.

Cheng, J., Lam, K.N., Engel, K., Hall, M., Neufeld, J.D., and Charles, T.C. (2017) Metagenomic cosmid libraries suitable for functional screening in proteobacteria. In Functional Metagenomics: Tools and Applications, Charles, T. C., Liles, M.R., and Sessitsch, A. (eds). Cham: Springer, pp. 1-11.

Cloutier, D.D., Alm, E.W., and McLellan, S.L. (2015) Influence of land use, nutrients, and geography on microbial communities and fecal indicator abundance at Lake Michigan beaches. Appl Environ Microbiol 81: 4904-4913.

Cloutier, D.D., and McLellan, S.L. (2017) Distribution and differential survival of traditional and alternative indicators of fecal pollution at freshwater beaches. Appl Environ Microbiol 83: e02881-e02816.

Colston, S.M., Fullmer, M.S., Beka, L., Lamy, B., Gogarten, J.P., and Graf, J. (2014) Bioinformatic genome comparisons for taxonomic and phylogenetic assignments using Aeromonas as a test case. mBio 5: e02136-e02114.

Connell, H., Agace, A., Klemm, P., Schembri, M., Mårild, S., and Svanborg, C. (1996) Type 1 fimbrial expression enhances Escherichia coli virulence for the urinary tract. Proc Natl Acad Sci USA 93: 9827-9832.

Crovadore, J., Soljan, V., Calmin, G., Chablais, R., Cochard, B., and Lefort, F. (2017) Metatranscriptomic and metagenomic description of the bacterial nitrogen metabolism in waste water wet oxidation effluents. Heliyon 3: e00427.

Davis, M.P.A., van Dongen, S., Abreu-Goodger, C., Bartonicek, N., and Enright, A.J. (2013) Kraken: a set of tools for quality control and analysis of high-throughput sequence data. Methods 63: 41-49.

de Gouw, D., Diavatopoulos, D.A., Bootsma, H.J., Hermans, P.W.M., and Mooi, F.R. (2011) Pertussis: a matter of immune modulation. FEMS Microbiol Rev 35: 441-474.

Droppo, I.G., Krishnappan, B.G., Liss, S.N., Marvin, C., and Biberhofer, J. (2011) Modelling sediment-microbial dynamics in the South Nation River, Ontario, Canada: towards the prediction of aquatic and human health risk. Water Res 45: 3797-3809.

Droppo, I.G., Liss, S.N., Williams, D., Nelson, T., Jaskot, C., and Trapp, B. (2009) Dynamic existence of waterborne pathogens within river sediment compartments. Implications for water quality regulatory affairs. Environ Sci Technol 43: 1737-1743.

Edge, T.A., and Hill, S. (2005) Occurrence of antibiotic resistance in Escherichia coli from surface waters and fecal pollution sources near Hamilton, Ontario. Can J Microbiol 51: 501-505. 
Falk, N., Chaganti, S.R., and Weisener, C.G. (2018) Evaluating the microbial community and gene regulation involved in crystallization kinetics of $\mathrm{ZnS}$ formation in reduced environments. Geochim Cosmochim Ac 220: 201-216.

Field, K.G., and Samadpour, M. (2007) Fecal source tracking, the indicator paradigm, and managing water quality. Water Res 41: 3517-3538.

Filenko, N., Spiro, S., Browning, D.F., Squire, D., Overton, T. W., Cole, J., and Constantinidou, C. (2007) The NsrR regulon of Escherichia coli K-12 includes genes encoding the hybrid cluster protein and the periplasmic, respiratory nitrite reductase. J Bacteriol 189: 4410-4417.

Gardner, A.M., Helmick, R.A., and Gardner, P.R. (2002) Flavorubredoxin, an inducible catalyst for nitric oxide reduction and detoxification in Escherichia coli. $J$ Biol Chem 277: 8172-8177.

Gilberthorpe, N.J., and Poole, R.K. (2008) Nitric oxide homeostasis in Salmonella typhimurium. Roles of respiratory nitrate reductase and flavohemoglobin. $J$ Biol Chem 283: 11146-11154.

Goltsman, D.S.A., Comolli, L.R., Thomas, B.C., and Banfield, J.F. (2015) Community transcriptomics reveals unexpected high microbial diversity in acidophilic biofilm communities. ISME J 9: 1014-1023.

Handelsman, J. (2004) Metagenomics: application of genomics to uncultured microorganisms. Microbiol Mol Biol Rev 68: 669-685.

Haraga, A., Ohlson, M.B., and Miller, S.I. (2008) Salmonella interplay with host cells. Nat Rev Microbiol 6: 53-66.

Heaney, C.D., Sams, E., Dufour, A.P., Brenner, K.P., Haugland, R.A., Chern, E., et al. (2012) Fecal indicators in sand, sand contact, and risk of enteric illness among beachgoers. Epidemiol 23: 95-106.

Heaney, C.D., Sams, E., Wing, S., Marshall, S., Brenner, K., Dufour, A.P., and Wade, T.J. (2009) Contact with beach sand among beachgoers and risk of illness. Am J Epidemiol 170: 164-172.

Henry, T., Couillault, C., Rockenfeller, P., Boucrot, E., Dumont, A., Schroeder, N., et al. (2006) The Salmonella effector protein PipB2 is a linker for kinesin-1. Proc Natl Acad Sci USA 103: 13497-13502.

Heß, S., Berendonk, T.U., and Kneis, D. (2018) Antibiotic resistant bacteria and resistance genes in the bottom sediment of a small stream and the potential impact of remobilization. FEMS Microbiol Ecol 94: fiy128.

Ishii, S, Yan, T., Shively, D.A., Byappanahalli, M.N., Whitman, R.L., and Sadowsky, M.J. (2006) Cladophora (Chlorophyta) spp. harbor human bacterial pathogens in nearshore water of Lake Michigan. Appl Environ Microbiol 72: 4545-4553.

Joo, H.-S., Fu, C.-I., and Otto, M. (2016) Bacterial strategies of resistance to antimicrobial peptides. Philos Trans $R$ Soc B 371: 20150292.

Kerr, J.M., DePinto, J.V., McGrath, D., Sowa, S.P., and Swinton, S.M. (2016) Sustainable management of Great Lakes watersheds dominated by agricultural land use. $J$ Great Lakes Res 42: 1252-1259.

Kopylova, E., Noé, L., and Touzet, H. (2012) SortMeRNA: fast and accurate filtering of ribosomal RNAs in metatranscriptomic data. Bioinformatics 28: 3211-3217.
Ksoll, W.B., Ishii, S., Sadowsky, M.J., and Hicks, R.E. (2007) Presence and sources of fecal coliform bacteria in epilithic periphyton communities of Lake Superior. Appl Environ Microb 73: 3771-3778.

Leimena, M.M., Ramiro-Garcia, J., Davids, M., van den Bogert, B., Smidt, H., Smid, E.J., et al. (2013) A comprehensive metatranscriptome analysis pipeline and its validation using human small intestine microbiota datasets. BMC Genomics 14: 530 .

Leonard, A.F.C., Zhang, L., Balfour, A.J., Garside, R., and Gaze, W.H. (2015) Human recreational exposure to antibiotic resistant bacteria in coastal bathing waters. Environ Int 82: 92-100.

Li, M., Lai, Y., Villaruz, A.E., Cha, D.J., Sturdevant, D.E., and Otto, M. (2007) Gram-positive three-component antimicrobial peptide-sensing system. Proc Natl Acad Sci USA 104: 9469-9474.

Locht, C., Bertin, P., Menozzi, F.D., and Renauld, G. (1993) The filamentous haemagglutinin, a multifaceted adhesion produced by virulent Bordetella spp. Mol Microbiol 9: 653-660.

Love, M.I., Huber, W., and Anders, S. (2014) Moderated estimation of fold change and dispersion for RNA-seq data with DESeq2. Genome Biol 15: 550.

Madsen, J.S., Burmølle, M., Hansen, L.H., and Sørensen, S. J. (2012) The interconnection between biofilm formation and horizontal gene transfer. FEMS Immunol Med Microbiol 65: 183-195.

Martinez, X., Pozuelo, M., Pascal, V., Campos, D., Gut, I., Gut, M., et al. (2016) MetaTrans: an open-source pipeline for metatranscriptomics. Sci Rep 6: 26447.

Mazar, J., and Cotter, P.A. (2006) Topology and maturation on filamentous haemagglutinin suggest a new model for two-partner secretion. Mol Microbiol 62: 641-654.

Melton, E.D., Stief, P., Behrens, S., Kappler, A., and Schmidt, C. (2014) High spatial resolution of distribution and interconnections between $\mathrm{Fe}$ - and $\mathrm{N}$-redox processes in profundal lake sediments. Environ Microbiol 16: 3287-3303.

Melvin, J.A., Scheller, E.V., Noël, C.R., and Cotter, P.A. (2015) New insight into filamentous hemagglutinin secretion reveals a role for full-length FhaB in Bordetella virulence. mBio 6: e01189-e01115.

Miao, E.A., Brittnacher, M., Haraga, A., Jeng, R.L., Welch, M.D., and Miller, S.I. (2003) Salmonella Effectors translocated across the vacuolar membrane interact with the Actin cytoskeleton. Mol Microbiol 48: 401-415.

Michalak, A.M., Anderson, E.J., Beletsky, D., Boland, S., Bosch, N.S., Bridgeman, T.B., et al. (2013) Record-setting algal bloom in Lake Erie caused by agricultural and meteorological trends consistent with expected future conditions. Proc Natl Acad Sci USA 110: 6448-6452.

Miller, M., and Bassler, B. (2001) Quorum sensing in bacteria. Annu Rev Microbiol 55: 165-199.

Mohan, S.B., Schmid, M., Jetten, M., and Cole, J. (2004) Detection and widespread distribution of the nrfA gene encoding nitrite reduction to ammonia, a short circuit in the biological nitrogen cycle that competes with denitrification. FEMS Microbiol Ecol 49: 433-443.

Mohiuddin, M.M., Salama, Y., Schellhorn, H.E., and Golding, B. (2017) Shotgun metagenomic sequencing 
reveals freshwater beach sands as reservoir of bacterial pathogens. Water Res 115: 360-369.

Molin, S., and Tolker-Nielsen, T. (2003) Gene transfer occurs with enhanced efficiency in biofilms and induces enhanced stabilisation of the biofilm structure. Curr Opin Biotech 14: 255-261.

Natural Resources Defense Council (NRDC). (2014) Testing the waters 2014: great lakes supplement.

Neira, J., Ortiz, M., Morales, L., and Acevedo, E. (2015) Oxygen diffusion in soils: understanding the factors and processes needed for modeling. Chil J Agr Res 75: 35-44.

Nieto, P.A., Covarrubias, P.C., Jedlicki, E., Holmes, D.S., and Quatrini, R. (2009) Selection and evaluation of reference genes for improved interrogation of microbial transcriptomes: case study with the extremophile Acidithiobacillus ferrooxidans. BMC Mol Biol 10: 63.

Niu, Q., and Xia, M. (2017) The role of wave-current interaction in Lake Erie's seasonal and episodic dynamics. $J$ Geophys Res-Oceans 122: 7291-7311.

Noël, C.R., Mazar, J., Melvin, J.A., Sexton, J.A., and Cotter, P.A. (2012) The prodomain of the Bordetella twopartner secretion pathway protein FhaB remains intracellular yet affects the conformation of the mature C-terminal domain. Mol Microbiol 86: 988-1006.

Pandey, P.K., Kass, P.H., Soupir, M.L., Biswas, S., and Singh, V.P. (2014) Contamination of water resources by pathogenic bacteria. $A M B$ Express 4: 51.

Paulson, J.N., Stine, O.C., Bravo, J.C., and Pop, M. (2013) Differential abundance analysis for microbial marker-gene surveys. Nat Methods 10: 1200-1202.

Peschel, A., Jack, R.W., Otto, M., Collins, L.V., Staubitz, P., Nicholson, G., et al. (2001) Staphylococcus aureus resistance to human defensins and evasion of neutrophil killing via the novel virulence factor MprF is based on modification of membrane lipids with L-lysine. J Exp Med 193: 1067-1076.

Peschel, A., Otto, M., Jack, R.W., Kalbacher, H., Jung, G., and Gotz, F. (1999) Inactivation of the dlt operon in Staphylococcus aureus confers sensitivity to defensins, protegrins, and other antimicrobial peptides. $J$ Biol Chem 274: 8405-8410.

Phillips, M.C., Feng, Z., Vogel, L.J., Reniers, A.J.H.M., Haus, B.K., Enns, A.A., et al. (2014) Microbial release from seeded beach sediments during wave conditions. Mar Pollut Bull 79: 114-122.

Poock, S.R., Leach, E.R., Moir, J.W.B., Cole, J.A., and Richardson, D.J. (2002) Respiratory detoxification of nitric oxide by the cytochrome $c$ nitrite reductase of Escherichia coli. J Biol Chem 277: 23664-23669.

Poole, R.K. (2005) Nitric oxide and nitrosative stress tolerance in bacteria. Biochem Soc Trans 33: 176-180.

Probandt, D., Eickhorst, T., Ellrott, A., Amann, R., and Knittel, K. (2018) Microbial life on a sand grain: from bulk sediment to single grains. ISME J 12: 623-633.

Pruesse, E., Quast, C., Knittel, K., Fuchs, B.M., Ludwig, W., Peplies, J., and Glöckner, F.O. (2007) SILVA: a comprehensive online resource for quality checking and aligned ribosomal RNA sequence data compatible with ARB. Nucleic Acids Res 35: 7188-7196.

Ramirez, K.S., Knight, C.G., de Hollander, M., Brearley, F. Q., Constantinides, B., Cotton, A., et al. (2018) Detecting macroecological patterns in bacterial communities across independent studies of global soils. Nat Microbiol 3: 189-196.

Reid, T., Chaganti, S.R., Droppo, I.G., and Weisener, C.G. (2018) Novel insights into freshwater hydrocarbon-rich sediments using metatranscriptomics: opening the black box. Water Res 136: 1-11.

Reid, T., VanMensel, D., Droppo, I.G., and Weisener, C.G. (2016) The symbiotic relationship of sediment and biofilm dynamics at the sediment water interface of oil sands industrial tailings ponds. Water Res 100: 337-347.

Remaut, H., Tang, C., Henderson, N.S., Pinkner, J.S., Wang, T., Hultgren, S.J., et al. (2008) Fiber formation across the bacterial outer membrane by the chaperone/usher pathway. Cell 133: 640-652.

Rissanen, A.J., Kurhela, E., Aho, T., Oittinen, T., and Tiirola, M. (2010) Storage of environmental samples for guaranteeing nucleic acid yields for molecular microbiological studies. Appl Microbiol Biotechnol 88: 977-984.

Rodionov, D.A., Dubchak, I.L., Arkin, A.P., Alm, E.J., and Gelfand, M.S. (2005) Dissimilatory metabolism of nitrogen oxides in bacteria: comparative reconstruction of transcriptional networks. PLoS Comput Biol 1: 0415-0431.

Rohmer, L., Hocquet, D., and Miller, S.I. (2011) Are pathogenic bacteria just looking for food? Metabolism and microbial pathogenesis. Trends Microbiol 19: 341-348.

Rusch, A., Huettel, M., Reimers, C.E., Taghon, G.L., and Fuller, C.M. (2003) Activity and distribution of bacterial populations in Middle Atlantic Bight shelf sands. FEMS Microbiol Ecol 44: 89-100.

Salk, K.R., Bullerjahn, G.S., McKay, R.M.L., Chaffin, J.D., and Ostrom, N.E. (2018) Nitrogen cycling in Sandusky Bay, Lake Erie: oscillations between strong and weak export and implications for harmful algal blooms. Biogeosciences 15: 2891-2907.

Shahraki, A.H., Chaganti, S.R., and Heath, D. (2019) Assessing high-throughput environmental DNA extraction methods for meta-barcode characterization of aquatic microbial communities. J Water Health 17: 37-49.

Solo-Gabriele, H., Harwood, V., Kay, D., Fujioka, R.S., Sadowsky, M.J., Whitman, R.L., et al. (2016) Beach sand and the potential for infectious disease transmission: observations and recommendations. J Mar Biol Assoc UK 96: 101-120.

Somerville, G.A., and Proctor, R.A. (2009) At the crossroads of bacterial metabolism and virulence factor synthesis in staphylococci. Microbiol Mol Biol Rev 73: 33-248.

Soumana, I.H., Linz, B., and Harvill, E.T. (2017) Environmental origin of the genus Bordetella. Front Microbiol 8: 28.

Sousa, A.J., Droppo, I.G., Liss, S.N., Warren, L., and Wolfaardt, G. (2015) Influence of wave action on the partitioning and transport of unattached and floc-associated bacteria in fresh water. Can J Microbiol 61: 584-596.

Spiro, S. (2012) Nitrous oxide production and consumption: regulation of gene expression by gas-sensitive transcription factors. Philos Trans R Soc B 367: 1213-1225.

Stewart, E.J. (2012) Growing unculturable bacteria. $J$ Bacteriol 194: 4151-4160.

Su, C., Lei, L., Duan, Y., Zhang, K., and Yang, J. (2012) Culture-independent methods for studying environmental 
microorganisms: methods, application, and perspective. Appl Microbiol Biotechnol 93: 993-1003.

Szeto, J., Namolovan, A., Osborne, S.E., Coombes, B.K., and Brumell, J.H. (2009) Salmonella-containing vacuoles display centrifugal movement associated with cell-to-cell transfer in epithelial cells. Infect Immun 77: 996-1007.

Tsoy, O.V., Ravcheev, D.A., Cuklina, J., and Gelfand, M.S. (2016) Nitrogen fixation and molecular oxygen: comparative genomic reconstruction of transcription regulation in Alphaproteobacteria. Front Microbiol 7: 1343.

Tucker, N.P., Le Brun, N.E., Dixon, R., and Hutchings, M.I. (2010) There's NO stopping NsrR, a global regulator of the bacterial NO stress response. Trends Microbiol 18: 149-156.

VanMensel, D., Chaganti, S.R., Boudens, R., Reid, T., Ciborowski, J.J.H., and Weisener, C.G. (2017) Investigating the microbial degradation potential in oil sands fluid fine tailings using gamma irradiation: a metagenomic perspective. Microb Ecol 74: 362-372.

Vo, A.-T.E., and Jedlicka, J.A. (2014) Protocols for metagenomic DNA extraction and Illumina amplicon library preparation for faecal and swab samples. Mol Ecol Resour 14: 1183-1197.

Wang, J., Yan, D., Dixon, R., and Wang, Y.-P. (2016) Deciphering the principles of bacterial nitrogen dietary preferences: a strategy for nutrient containment. mBio 7: e00792-e00716.

Weisener, C.G., Lee, J., Chaganti, S.R., Reid, T., Falk, N., and Drouillard, K. (2017) Investigating sources and sinks of $\mathrm{N}_{2} \mathrm{O}$ expression from freshwater microbial communities in urban watershed sediments. Chemosphere 188: 697-705.

Whitman, R.L., Harwood, V.J., Edge, T.A., Nevers, M.B., Byappanahalli, M., Vijayavel, K., et al. (2014) Microbes in beach sands: integrating environment, ecology and public health. Rev Environ Sci Biotechnol 13: 329-368.

Wilke, A., Bischof, J., Harrison, T., Brettin, T., D'Souza, M., Gerlach, W., et al. (2015) A RESTful API for accessing microbial community data for MG-RAST. PLoS Comput Biol 11: e1004008.

Wood, D.E., and Salzberg, S.L. (2014) Kraken: ultrafast metagenomic sequence classification using exact alignments. Genome Biol 15: R46.

Xie, Y., Wang, J., Wu, Y., Ren, C., Song, C., Yang, J., et al. (2016) Using in situ bacterial communities to monitor contaminants in river sediments. Environ Pollut 212: 348-357.

Yamahara, K.M., Walters, S.P., and Boehm, A.B. (2009) Growth of enterococci in unaltered, unseeded beach sands subjected to tidal wetting. Appl Environ Microbiol 75: 1517-1524.

Yilmaz, P., Parfrey, L.W., Yarza, P., Gerken, J., Pruesse, E., Quast, C., et al. (2014) The SILVA and "All-species Living Tree Project (LTP)" taxonomic frameworks. Nucleic Acids Res 42: 643-648.

Zaitseva, J., Jenewein, S., Jumpertz, T., Holland, I.B., and Schmitt, L. (2005) H662 in the linchpin of ATP hydrolysis in the nucleotide-binding domain of the $A B C$ transporter HlyB. EMBO J 24: 1901-1910.

Zhang, X., Lui, X., Liang, Y., Xiao, Y., Ma, L., Guo, X., et al. (2017) Comparative genomics unravels the functional roles of co-occuring acidophilic bacteria in bioleaching heaps. Front Microbiol 8: 790.

Zimmer-Faust, A.G., Thulsiraj, V., Marambio-Jones, C., Cao, Y., Griffith, J.F., Holden, P.A., and Jay, J.A. (2017) Effect of freshwater sediment characteristics on the persistence of fecal indicator bacteria and genetic markers within a Southern California watershed. Water Res 119: 1-11.

\section{Supporting Information}

Additional Supporting Information may be found in the online version of this article at the publisher's web-site:

Figure S1 Line graph depicting the percentage of incidences that reported CFU values of indicator $E$. coli in the water at WEC public beaches exceeded acceptable levels over the past 7 years. Thick solid lines indicate locations of interest to this manuscript (Belle River (BR), Holiday (HD), Kingsville $(\mathrm{KV})$, Sandpoint $(\mathrm{SP})$ ), and thin dashed lines represent the other beaches monitored. Data provided by WECHU. Note: up until 2017, acceptable $E$. coli levels were less than $100 \mathrm{CFUs} / 100 \mathrm{~mL} ; 2018$ it changed to $200 \mathrm{CFUs} / 100 \mathrm{~mL}$.

Table S1 Summary of sequencing statistics for metabarcoding data obtained from the lon Torrent PGM

Table S2 Summary of sequencing statistics for all samples obtained from the Illumina HiSeq 4000 run 